Full Length Article

\title{
Synergic effect of ozonation and electrochemical methods on oxidation and toxicity reduction: Phenol degradation
}

\author{
Deysi Amado-Piña, Gabriela Roa-Morales*, Carlos Barrera-Díaz, Patricia Balderas-Hernandez, \\ Rubí Romero, Eduardo Martín del Campo, Reyna Natividad*
}

Centro Conjunto de Investigación en Química Sustentable CCIQS, UAEM-UNAM, Facultad de Química, Universidad Autónoma del Estado de México, UAEMex Carretera Toluca-Atlacomulco, km 14.5, C.P. 50200 Toluca, Mexico

\section{H I G H L I G H T S}

- $\mathrm{O}_{3}$-EO enhances by 2.5 times the mineralization of phenol when compared to $\mathrm{O}_{3}$ alone.

- $\mathrm{O}_{3}$-EO reduces by half the time to achieve a phenol mineralization $>90 \%$.

- Ozonation alone fails on phenol mineralization and on diminishing toxicity.

- Toxicity onto Latuca sativa is only eliminated by the coupled treatment $\left(\mathrm{O}_{3}\right.$-EO).

\section{A R T I C L E I N F O}

\section{Article history:}

Received 15 May 2016

Received in revised form 23 October 2016

Accepted 26 October 2016

Available online 3 November 2016

\section{Keywords:}

Ozone

BDD

AOPs

Ozone-BDD coupled process

Root elongation (RE)

Germination Index (GI)

Electroperoxonation
G R A P H I C A L A B S T R A C T

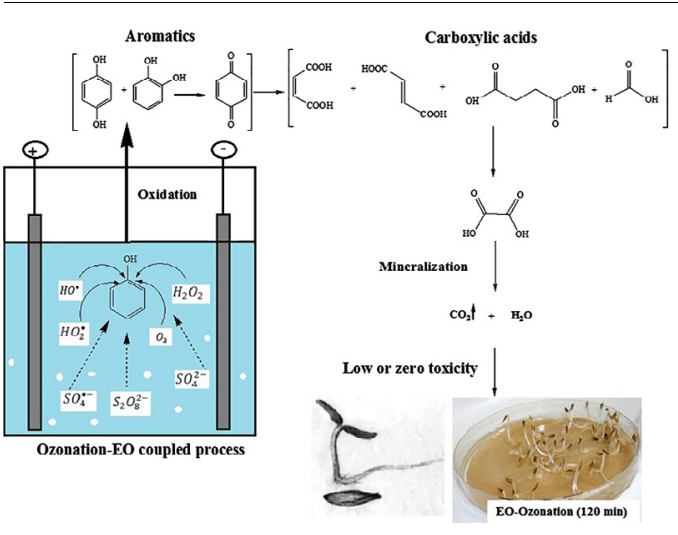

\section{A B S T R A C T}

The degradation of phenol was studied under three chemical environments, ozonation $\left(\mathrm{O}_{3}\right)$, electrooxidation (EO) and ozonation-electro-oxidation $\left(\mathrm{O}_{3}\right.$-EO) coupled process. The parent compound concentration was established by UV-Vis spectrophotometry while the by-products were identified by HPLC. This allowed proposing a mechanism of phenol oxidation during the coupled process. This coupled process was found to practically mineralize all phenol (TOC removal $=99.8 \%$ ) under $\mathrm{pH} 7.0 \pm 0.5$ and at a current density of $60 \mathrm{~mA} \mathrm{~cm}^{-2}, 0.05 \mathrm{~L} \mathrm{~min}^{-1}$ flowrate, ozone concentration of $5 \pm 0.5 \mathrm{mg} \mathrm{L}^{-1}$. Furthermore, it was found that the coupled process is practically twice faster than the EO process alone to achieve a high degree of mineralization. In this sense, it was concluded that ozone alone only partially mineralizes the phenol molecule and mainly leads to the formation of aliphatic compounds. In addition, the toxicities of phenol and its degradation products were established by using a bioassay with lettuce seeds. It was concluded that, unlike ozonation, the coupled oxidation process not only mineralizes the organic molecule but also completely eliminates the toxicity of the treated phenolic solution.

(c) 2016 Elsevier Ltd. All rights reserved.

\footnotetext{
* Corresponding authors.

E-mail addresses: groam@uaemex.mx (G. Roa-Morales), reynanr@gmail.com (R. Natividad)
}

\section{Introduction}

Some main organic pollutants of water are oil, gasoline, plastics, pesticides, solvents and detergents, among many other watersoluble and water-insoluble chemicals that threat human health 
and damage aquatic life. Some of these substances can cause kidney disorders, birth defects and various cancers even at very small concentration. This is the case of phenolic compounds, which are used in a wide variety of industrial processes such as the production of pesticides, resins, nylon, antioxidants, plasticizers, drugs, dyes, explosives, oil additives and disinfectants [1-3]. In this context and due to its toxicity and persistence, phenol mineralization is of paramount importance for the environment protection. To achieve so, several technologies are available. However, among all these treatments, Advanced Oxidation Processes (AOP's) emerge as promising methods for wastewater treatment because they have been reported to be relatively simple, easy to control, and result in a high oxidation degree and compatibility with the environment [4-7].

Ozonation $\left(\mathrm{O}_{3}\right)$ and electro-oxidation (EO) chemical methods can be found among these AOP's. Some information considered as relevant of each treatment and helpful to improve the understanding of the coupled treatment is below presented.

\subsection{Ozonation}

Ozone $\left(\mathrm{O}_{3}\right)$ is a weak polar $(0.53 \mathrm{D})$ and highly reactive molecule that exhibits a high redox potential (2.07 V vs. NHE) only below atomic oxygen ( $2.42 \mathrm{~V}$ vs. NHE) [8]. In wastewater treatment, ozone can play different roles and these are mainly: disinfectant or biocide, oxidant to remove organic pollutants, and as pre-or post-treatment agent to aid other processes, i.e. flocculation or sedimentation [9].

In ozonation, the oxidation of organic pollutants can occur via (a) direct electrophilic attack by molecular ozone (known also as ozonolysis) and this proceeds at acidic or neutral $\mathrm{pH}$ and is a selective reaction resulting in the formation of carboxylic acids as end products that cannot be oxidized further by molecular ozone and (b) indirect attack through the formation of stronger oxidant species like hydroxyl radicals (HO) $[10,11]$. Therefore, the $\mathrm{pH}$ of the effluent is a major factor determining the efficiency of the ozonation process since it can alter both, the chemistry and kinetics of the oxidation process.

The generation of hydroxyl radicals occurs by the following reactions (1)-(11) [12],

$$
\begin{aligned}
& \mathrm{O}_{3}+\mathrm{OH}^{-} \rightarrow \mathrm{HO}_{2}^{-}+\mathrm{O}_{2} \\
& \mathrm{O}_{3}+\mathrm{HO}_{2}^{-} \rightarrow \mathrm{HO}_{2}^{-}+\mathrm{O}_{3}^{-\cdot} \\
& \mathrm{HO}_{2}^{-} \rightarrow \mathrm{O}_{2}^{-\cdot}+\mathrm{H}^{+} \\
& \mathrm{O}_{2}^{-\cdot}+\mathrm{H}^{+} \rightarrow \mathrm{HO}_{2}^{\cdot} \\
& \mathrm{O}_{3}+\mathrm{O}_{2}^{-} \rightarrow \mathrm{O}_{3}^{-\cdot}+\mathrm{O}_{2} \\
& \mathrm{O}_{3}^{-\cdot}+\mathrm{H}_{2} \mathrm{O} \rightarrow \mathrm{HO}^{\cdot}+\mathrm{O}_{2}+\mathrm{OH}^{-} \\
& \mathrm{O}_{3}^{-}+\mathrm{HO}^{\cdot} \rightarrow \mathrm{HO}_{2}^{-}+\mathrm{O}_{2}^{-\cdot} \\
& \mathrm{O}_{3}+\mathrm{HO}^{\cdot} \rightarrow \mathrm{HO}_{2}^{-}+2 \mathrm{O} \\
& \mathrm{HO}_{2}^{-}+\mathrm{H}^{+} \rightarrow \mathrm{H}_{2} \mathrm{O}_{2} \\
& \mathrm{H}_{2} \mathrm{O}_{2} \rightarrow \mathrm{HO}_{2}^{-}+\mathrm{H}^{+} \\
& \mathrm{O}_{3}+\mathrm{HO}^{\cdot} \rightarrow \mathrm{O}_{3}+\mathrm{OH}^{-}
\end{aligned}
$$

These reactions are promoted either under alkaline conditions or under the presence of initiators like hydrogen peroxide or ultraviolet light. Yet, the improvement of ozonation efficiency is desirable in order to decrease ozone consumption and to fully oxidize compounds like humic substances or oxalic acid [8]. In this sense, the coupling of ozonation and electrochemical treatment has already been proven [13-16] to exert a positive synergic effect on oxidation rate and mineralization degree.

\subsection{Electro-oxidation}

This process consists on the generation of highly oxidant species by electrolysis. The main operational variables affecting the efficiency of this process are $\mathrm{pH}$, current density, electrochemical cell design, physicochemical properties of reacting solution, electrolyte type and concentration, pollutant concentration and nature, electrodes material and geometry. The most oxidizing specie produced during electro-oxidation is the hydroxyl radical (HO') at the anode surface [17] by water oxidation. The availability of oxygen is also important since can be reduced to hydrogen peroxide or water at the cathode under acidic $\mathrm{pH}$. The produced hydrogen peroxide can then react with the hydroxyl radicals at the anode to generate hydroperoxyle radicals (reaction (12)),

$\mathrm{H}_{2} \mathrm{O}_{2}+\mathrm{HO}^{\circ} \rightarrow \mathrm{H}_{2} \mathrm{O}+\mathrm{HO}_{2}$

Nevertheless, the low efficiency of the anode has motivated the assessment of a wide variety of electrode materials such as graphite [18], platinum [19], $\mathrm{IrO}_{2}$ [20], $\mathrm{RuO}_{2}$ [21], $\mathrm{SnO}_{2}$ [22], $\mathrm{PbO}_{2}$ [23] and boron-doped diamond (BDD) [17]. Among all these materials, $\mathrm{PbO}_{2}$ and $\mathrm{BDD}$ electrodes are more attractive because of its high oxygen overpotential [24].

However, previously conducted research $[25,26]$ suggests that caution must be taken when BDD electrodes are used for the oxidation of chloride-containing waters because BDD electrodes can form twice faster $\mathrm{ClO}_{4}^{-}$than other electrodes, i.e. $\mathrm{Pt}, \mathrm{IrO}_{2}, \mathrm{IrO}_{2}$, $\mathrm{RuO}_{2}$. This has been ascribed to the ability of the BDD electrodes to promote the interaction between $\mathrm{ClO}_{3}$ and $\mathrm{HO}^{*}$ at high concentrations resulting in the production of $\mathrm{ClO}_{4}^{-}, \mathrm{ClO}_{3}^{-}$, or $\mathrm{ClO}_{2}$, chlorine $\left(\mathrm{Cl}_{2}\right)$ and hypochlorous acid/hypochlorite $\left(\mathrm{HOCl} / \mathrm{OCl}^{-}\right)$and other compounds (i.e. halogens). The detrimental effect of chlorides has been suggested [25] to be minimized by working at relative low current densities $\left(\leqslant 50 \mathrm{~A} \mathrm{~m}^{-2}\right)$. Other disadvantage of using BDD electrodes is their high cost mainly due to the substrate $(\mathrm{Nb}, \mathrm{W}, \mathrm{Ta})$ onto which the BDD film is deposited.

In the context of electrochemical technologies, it is of paramount importance to reduce the treatment time without sacrificing efficiency since many electrodes exhibit a relative short life and high cost. It should be kept on mind that electrochemical treatment time is directly correlated with energy consumption and therefore treatment cost. This has motivated the coupling with other treatments like ozonation.

\subsection{Ozonation-electrooxidation coupled process $\left(\mathrm{O}_{3}-\mathrm{EO}\right)$}

This process consists on the addition of ozone to the electrochemical cell where an oxidation is being conducted. If hydrogen peroxide is demonstrated to be in-situ produced then this treatment is also known as electroperoxonation. The in-situ hydrogen peroxide production is expected to occur, as abovementioned, by the cathodic reduction of oxygen under acidic conditions. The source of oxygen can be either the ozone stream or some ozone reactions (i.e. reactions (1), (5) and (6)). It has been shown [27] that when a carbon-PTFE electrode is used as cathode and other material as anode, a high hydrogen peroxide concentration is achieved.

Despite the disadvantages of BDD electrodes mentioned in Section 1.2, the anodic oxidation with this type of electrodes has received special attention [28,29]. Actually, high concentrations of hydrogen peroxide have also been achieved when BDD electrodes are used as anode and cathode. 
Although previous research [13-15] indicates important results when electrochemical oxidation using boron-doped diamond electrodes is coupled with ozone, the studies regarding this integrated process are rather scarce. Moreover, to the best of authors knowledge, there are only few studies [16,27] on the coupled process efficiency to remove pollutants and eliminate toxicity. Therefore, the main objective of this work was to compare the efficiency of three treatments, ozonation, electro-oxidation and coupled ozonation-electrooxidation, to mineralize and eliminate the toxicity of a phenol solution.

\section{Methods and materials}

\subsection{Phenol synthetic solution}

The phenol $(\mathrm{Ph})$ solution to be treated was a synthetic one with a $100 \mathrm{mg} \mathrm{L}^{-1} \mathrm{Ph}$ initial concentration. For this purpose, a stock phenol solution (1000 $\mathrm{mg} \mathrm{L}^{-1}$ ) was prepared using phenol (99.5\% purity, Merck) and deionized water. Then, aliquots $(100 \mathrm{~mL})$ of the stock solution were mixed with $900 \mathrm{~mL}$ of sodium sulfate $\left(\mathrm{Na}_{2} \mathrm{SO}_{4}\right)$ supporting electrolyte solution $(0.1 \mathrm{M})$. The employed $\mathrm{Na}_{2} \mathrm{SO}_{4}$ was Sigma-Aldrich 99\%.

\subsection{Ozonation}

The ozonation experiments were conducted in the up-flow glass bubble column reactor depicted in Fig. 1 although without the electrodes and power supply. Ozone was supplied by a Pacific Ozone Technology generator. A gas mixture ozone/air was continuously fed to the reactor at its inferior part through a gas diffuser $\left(0.2 \mathrm{~mm}\right.$ pore size) at a flowrate of $0.05 \mathrm{~L} \mathrm{~min}^{-1}$. The ozone concentration in this stream was $5 \pm 0.5 \mathrm{mg} \mathrm{L}^{-1}$. The excess of ozone in the outlet gas was decomposed by an ozone destructor. The solution degraded by this technique was $0.9 \mathrm{~L}$ of $100 \mathrm{mg} \mathrm{L}^{-1}$ phenol solution. This was prepared in deionized water. Samples were taken at specific time intervals to determine Chemical Oxygen Demand (COD), Total Organic Carbon (TOC), toxicity with lettuce (Lactuca sativa) seeds and to be analyzed by UV-Vis spectroscopy and High-Performance Liquid Chromatography (HPLC). All the experiments were carried out at room temperature $\left(20^{\circ} \mathrm{C} \pm 2\right)$, initial
pH was adjusted to $7.0 \pm 0.5$ with sodium hydroxide ACS pellets (Sigma-Aldrich 97\%).

\subsection{Electro-oxidation (EO)}

This process was conducted in the experimental set up depicted in Fig. 1 without the ozone generator though. The reactorelectrochemical cell contained a pair of BDD electrodes (BDD film supported on a niobium substrate). Each electrode was $20.0 \mathrm{~cm}$ by $2.5 \mathrm{~cm}$ with a surface area of $50 \mathrm{~cm}^{2} .0 .9 \mathrm{~L}$ of phenol solution (100 $\mathrm{mg} \mathrm{L}^{-1}$ ) were prepared and transferred to the electrochemical cell. A direct-current power source supplied the system with 1.0, 2.0 and 3.0 A corresponding to current densities of 20,40 , and $60 \mathrm{~mA} \mathrm{~cm}^{-2}$. All the experiments were carried out at room temperature $\left(20^{\circ} \mathrm{C} \pm 2\right)$ and initial $\mathrm{pH}=7.0$. $\mathrm{pH}$ was monitored but not controlled at all experiments.

\subsection{Ozonation-electrooxidation coupled process $\left(\mathrm{O}_{3}-\mathrm{EO}\right)$}

For the combined system the pair of BDD electrodes from the electrochemical reactor were installed in the ozonation reactor as shown in Fig. 1.

A direct-current power source supplied the system with $3.0 \mathrm{~A}$ that corresponds to a current density of $60 \mathrm{~mA} \mathrm{~cm}^{-2}$. All the experiments were carried out at room temperature $\left(20^{\circ} \mathrm{C} \pm 2\right)$ and initial $\mathrm{pH}=7.0 \pm 0.5$. Treated samples were taken at the same intervals than with the individual treatments and equally analyzed.

\subsection{Chemical analysis}

Phenol concentration in solution was determined by UV/Vis spectrophotometry by applying the method of 4-aminoantipyrine (Sigma Aldrich reagent grade) in the presence of potassium ferrocyanide (Baker 99.8\%) as described by Carrillo and co-workers 2014 [30]. The produced compounds are of intense red-yellow color, and this allows to directly measure absorbance by using a PerkinElmer Model Lambda 25 UV/Vis spectrophotometer. Samples absorbance was scanned from 200 to $900 \mathrm{~nm}$ and a maximum absorbance at $510 \mathrm{~nm}$ was observed. The samples were scanned in a quartz cell with $1 \mathrm{~cm}$ optical path. In order to establish the

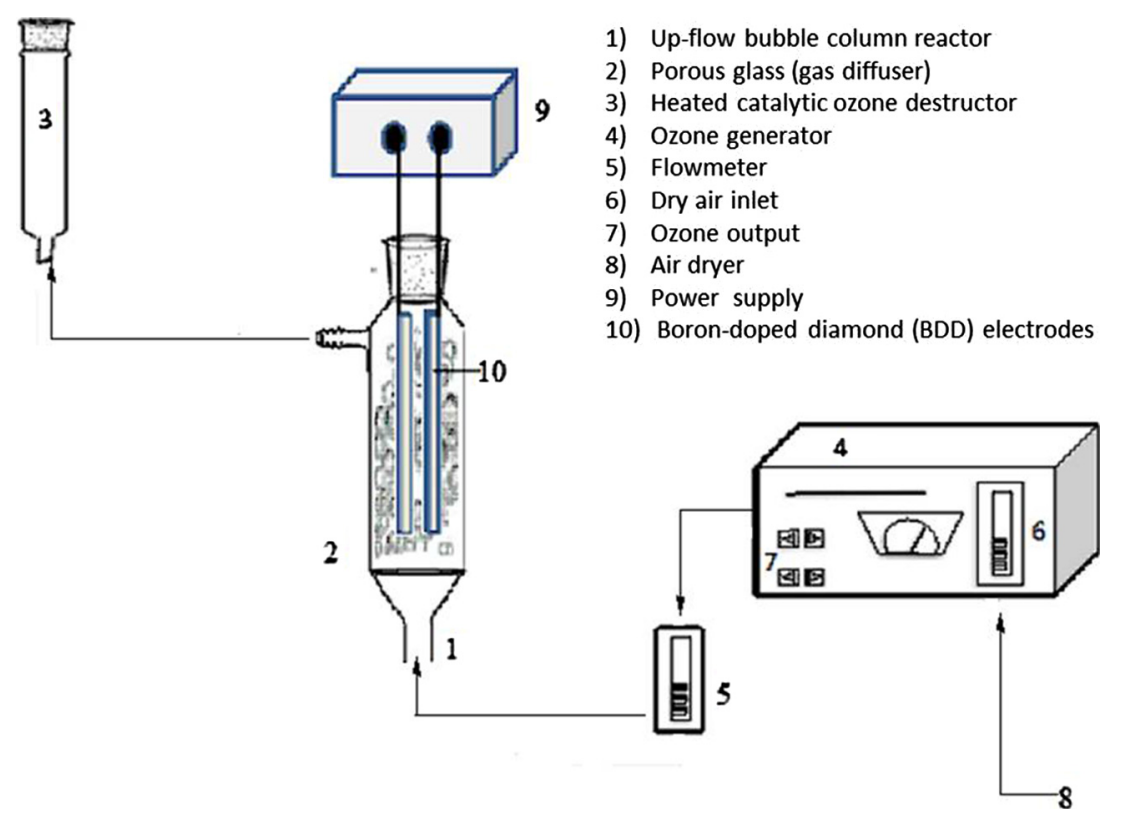

Fig. 1. Schematic apparatus for the ozonation, electro-oxidation and ozonation-electrooxidation processes. 
mineralization degree of phenol, Chemical Oxygen Demand (COD) and Total Organic Carbon (TOC) of samples was determined by means of the American Public Health Association (APHA) standard procedures [31], by using a Hach DR 5000 and TOC-L Shimadzu Total Organic Carbon analyzer for COD and TOC measurements, respectively.

The control of phenol decomposition as well as the intermediates and final products identification was performed by a high performance liquid chromatograph equipped with a UV-Vis detector series Waters 2487 Dual $\lambda$, using Waters 1515 Isocratic Pump. Data analysis was performed using Breeze 2 software. Separation was isocratically achieved at $25^{\circ} \mathrm{C}$. For the identification of carboxylic acids by high performance liquid chromatography (HPLC), the mobile phase consisted of water:acetonitrile:phosphoric acid (89.9:10:0.1 v/v) and was pumped at a flow rate of $0.6 \mathrm{~mL} \mathrm{~min}{ }^{-1}$. The injection volume was $20 \mu \mathrm{L}$. The identification wavelength was set at $210 \mathrm{~nm}$. A reverse phase column was employed (Eclipse ${ }^{\circledR}$ XDB C-18, $15.0 \mathrm{~cm}$ in length and $4.6 \mathrm{~mm}$ in diameter, Agilent). To separate and identify the aromatic compounds by HPLC, the mobile phase consisted of methanol-water $(80: 20 \mathrm{v} / \mathrm{v}$ and $5 \mathrm{mM}$ of $\mathrm{H}_{2} \mathrm{SO}_{4}$ ) and was pumped at a flow rate of $1.0 \mathrm{~mL} \mathrm{~min}^{-1}$. The injection volume was $20 \mu \mathrm{L}$. The quantification wavelength was set at $280 \mathrm{~nm}$. The employed column was Ascentis ${ }^{\circledR}$ Express C-18 (Supelco), $3.0 \mathrm{~cm}$ in length and $4.6 \mathrm{~mm}$ in diameter.

Hydrogen peroxide concentration profile was determined during each treatment by a colorimetric method [32], using titanium sulfate $\left(\mathrm{Ti}^{4+}\right)$ reagent and measuring the color intensity (yellow color) of solutions at a wavelength of $408 \mathrm{~nm}$.

\subsection{Toxicity bioassay}

A toxicity bioassay with lettuce (Lactuca sativa) seeds was carried out. This is a static severe toxicity test $(120 \mathrm{~h})$ that is applied to establish the phytotoxic effects on seedling by monitoring the seeds development during the first days of growth. In this work, a bioassay with lettuce seeds was carried out according to Dutka method (1991) [33]. In the test, 20 seeds of similar size, shape and color, were taken. Commercially available plant seeds were used. They were evenly distributed over Whatman No. 1 paper in a Petri dish. Three replicates of each control sample were prepared (deionized water and $\mathrm{Na}_{2} \mathrm{SO}_{4} 0.1 \mathrm{M}$ ), and samples from the 3 different applied treatments $\left(\mathrm{O}_{3}\right.$, EO and $\mathrm{O}_{3}$-EO) were assessed. From each treatment, samples $(5 \mathrm{~mL})$ were collected at different reaction times $0,5,10,20,30$ 40, 50, 60, 90, 100, 110 and 120 min. Such samples were kept under constant temperature of $22 \pm 2{ }^{\circ} \mathrm{C}$ and darkness for 5 days (exposure time). After the seeds incubation period, the average length of seed roots was measured and recorded for each sample. When the exposure period ended, the effect on seed germination and elongation of the radicle was quantified.

In order to calculate the Germination Index (GI), the relative seed germination (RSG) and the growth relative of radicle (GRR) were calculated by means of Eqs. (1) and (2), respectively [34,35].

$$
\begin{aligned}
R S G= & \frac{\text { number of germinated seeds in the sample }}{\text { number of germinated seeds in the control sample }} \\
& \times 100
\end{aligned}
$$

$G R R=\frac{\text { Length average radicle in the sample }}{\text { Length average radicle in control sample }} \times 100$

GI is a more specific indicator that takes into account the interaction of factors promoting or inhibiting the seed germination with factors favoring or inhibiting the growth of the species radical or seed germination. The GI is calculated by means of Eq. (3),
$G I=\frac{R S G \times G R R}{100}$

GI values near $100 \%$ indicate low or zero toxicity (L), GI values below $50 \%$ indicate that toxicity is moderated (M) and GI values near 0 indicate the toxicity or phytotoxicity is high or maximum $(\mathrm{H})$.

\section{Results and discussion}

\subsection{Electro-oxidation (EO) treatment}

The influence of current density on the treatment efficiency of the electrochemical system was studied at 20,40 and $60 \mathrm{~mA} \mathrm{~cm}^{-2}$. Fig. 2 shows that the phenol removal percentage increases with electrolysis time and the removal rate increased with the applied current density. After 120 min of electrolysis, the phenol degradation efficiency reached $81 \%, 93 \%$ and $98 \%$ with current densities of 20,40 and $60 \mathrm{~mA} \mathrm{~cm}^{-2}$, respectively. It can also be observed that the decay of phenol concentration exhibited an exponential behavior with all the applied currents. These results concur with those previously reported [36] when applying a high current density $\left(60 \mathrm{~mA} \mathrm{~cm}^{-2}\right)$ to a low phenol concentration $\left(100 \mathrm{mg} \mathrm{L}^{-1}=\right.$ $1.1 \mathrm{mM}$ ) solution.

During electrolysis, the anodes favor the electro-generation of HO- radicals. These are adsorbed at the electrode surface and are the product of water oxidation. In an acid or neutral medium, the HO* radicals are directly generated at the anode and are the products in the direct oxidation of water that occurs according to reaction (13) [29],

$\mathrm{BDD}+\mathrm{H}_{2} \mathrm{O} \rightarrow \mathrm{BDD}+\mathrm{HO}^{\cdot}+\mathrm{H}^{+}+\mathrm{e}^{-}$anodic oxidation

Then, the oxidation of organic compounds with concomitant oxygen evolution (reactions (14) and (15)) take place on the BDD anode surface via hydroxyl radicals electro-generated from reaction (13) [4]. Reaction (14) is in competition with the side reaction of $\mathrm{HO}$ conversion to $\mathrm{O}_{2}$ (reaction (15)).

$$
\begin{aligned}
& B D D\left(\mathrm{HO}^{*}\right)+\mathrm{R} \rightarrow \mathrm{BDD}+\mathrm{mCO}_{2}+n \mathrm{H}_{2} \mathrm{O} \\
& B D D\left(\mathrm{HO}^{*}\right) \rightarrow B D D+\frac{1}{2} \mathrm{O}_{2}+\mathrm{H}^{+}+e^{-}
\end{aligned}
$$

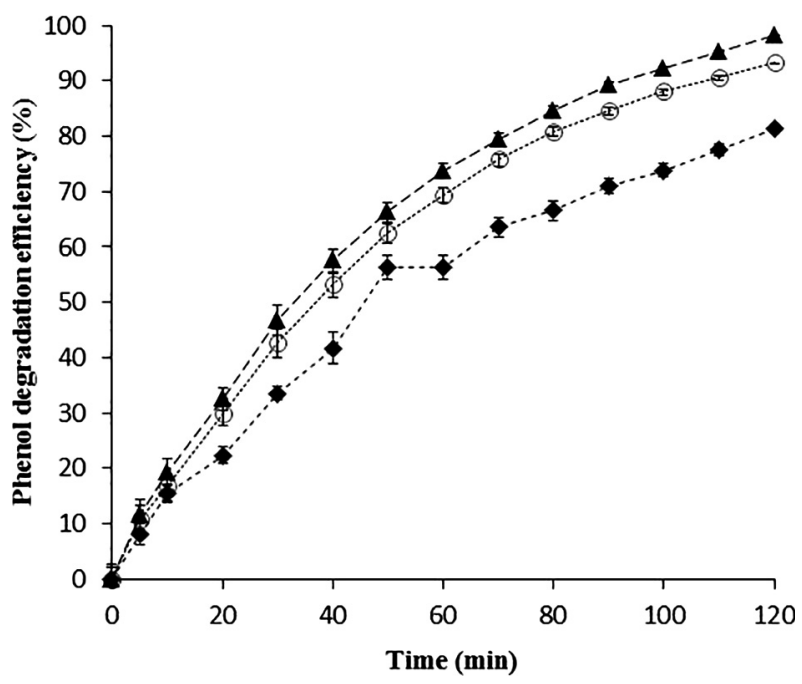

Fig. 2. Effect of current density (४) $20 \mathrm{~mA} \mathrm{~cm}^{-2}(\bigcirc) 40 \mathrm{~mA} \mathrm{~cm}^{-2}$ (४) $60 \mathrm{~mA} \mathrm{~cm}^{-2}$ on the phenol removal efficiency in the electro-oxidation (EO) system. Initial $\mathrm{pH}=7.0,[\mathrm{Ph}]_{\mathrm{o}}=100 \mathrm{mg} \mathrm{L}^{-1}, \mathrm{~V}=0.9 \mathrm{~L}$. 
Concomitantly to water oxidation, the generation of hydrogen peroxide $\left(\mathrm{H}_{2} \mathrm{O}_{2}\right)$ is expected to occur by the oxygen reduction at the cathode by means of reaction (16) $[37,38]$,

$\mathrm{O}_{2}+2 \mathrm{H}^{+}+2 e^{-} \rightarrow \mathrm{H}_{2} \mathrm{O}_{2}$ cathodic reduction $E^{\circ}=0.440 \mathrm{~V}$

In this case, the in situ generation of hydrogen peroxide was confirmed and its concentration evolution with time can be observed in Fig. 3. It is worth clarifying that this concentration indicates the amount of accumulated $\mathrm{H}_{2} \mathrm{O}_{2}$ and not the generated one.

It is also worth mentioning, that under high current densities and acidic medium, oxygen is likely to be reduced towards water by means of reaction (17) [38],

$\mathrm{O}_{2}+4 \mathrm{H}^{+}+4 e^{-} \rightarrow 2 \mathrm{H}_{2} \mathrm{O}$ cathodic reduction $E^{\circ}=0.987 \mathrm{~V}$

This reaction is plausible to occur although will be limited by oxygen concentration and $\mathrm{pH}$.

It can be observed in Fig. 4, that within 5 min of reaction the $\mathrm{pH}$ becomes acid and this can be ascribed to the appearance of oxalic, succinic and formic acids (see Fig. 9). This change in $\mathrm{pH}$ is expected to aid reactions (16) and (17) to proceed. Actually, the accumulated hydrogen peroxide is observed to increase during the first $40 \mathrm{~min}$ (Fig. 3). After this time, $\mathrm{pH}$ slowly becomes neutral again since most of the acids are also consumed. This $\mathrm{pH}$ increase might be blamed for the $\mathrm{H}_{2} \mathrm{O}_{2}$ concentration decrease observed after 40 min of treatment time.

The initial COD and TOC values after 120 min of electrochemical treatment time are shown in Table 1 . By using these values the COD and TOC reduction\% can be calculated. The initial theoretical values of COD and TOC are 76.6 and $238.3 \mathrm{mg} / \mathrm{L}$, respectively. The initial values shown in Table 1, however, differ from the theoretical ones because they were measured by the corresponding techniques and therefore include experimental and instrumental errors. After 120 min of treatment, a COD reduction of $97.7 \%$ and 92.1\% TOC removal was reached. This indicates that the electrolysis not only degrades the phenol molecule but also mineralizes it (Fig. 9). From this figure, it can also be concluded that the most reluctant compound to be oxidized by EO is oxalic acid.

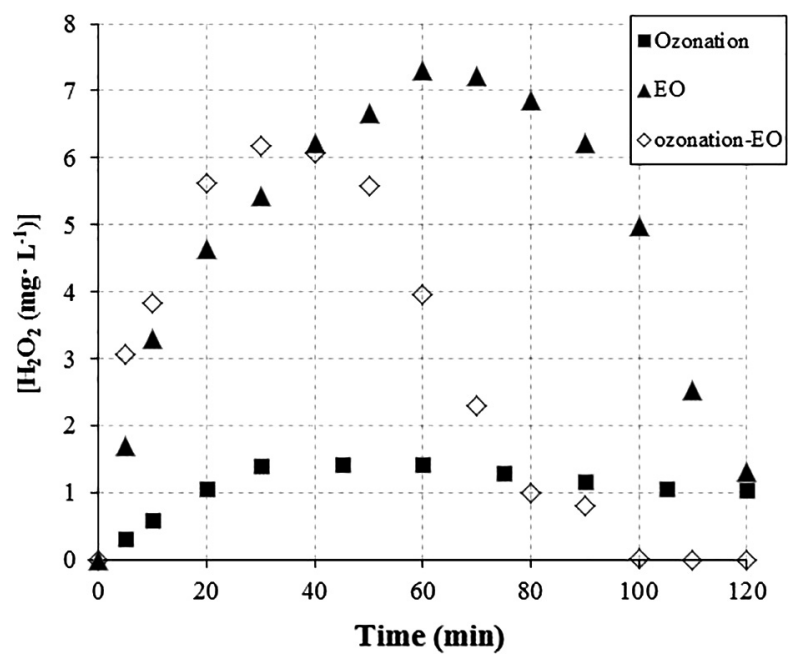

Fig. 3. $\mathrm{H}_{2} \mathrm{O}_{2}$ concentration as function of time and applied process $\left(\mathrm{O}_{3}\right.$, EO or $\left.\mathrm{O}_{3}-\mathrm{EO}\right)$.

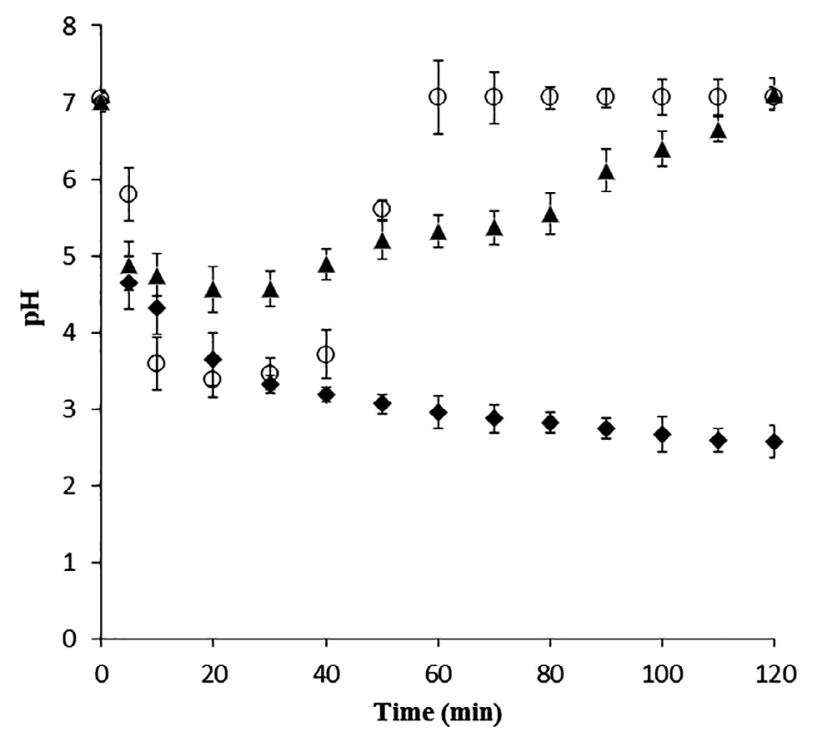

Fig. 4. Effect of type of treatment $(\diamond) \mathrm{O}_{3},(\Delta) \mathrm{EO}$ and $(\mathrm{O}) \mathrm{O}_{3}$-EO on pH evolution of phenol solution.

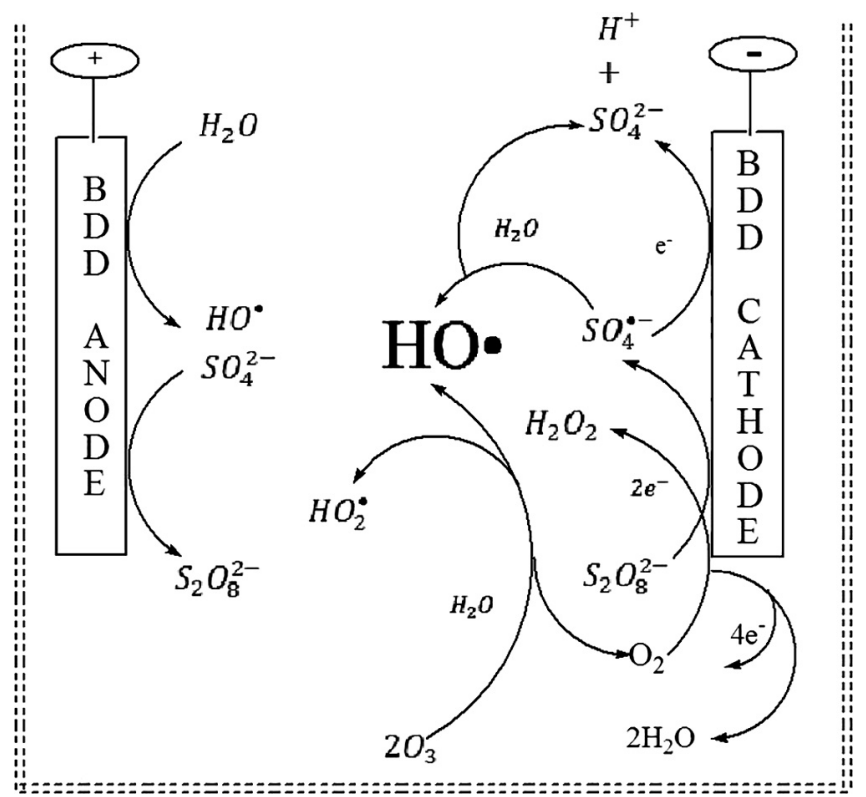

Fig. 5. Coupled ozonation-electrooxidation process conducted with BDD electrodes: proposed simplified mode of action and side products.

\subsection{Ozonation $\left(\mathrm{O}_{3}\right)$ treatment}

During the ozonation treatment of the phenol solution, both COD and TOC were monitored with time. The maximum COD reduction was $63.3 \%$ and the TOC removal was of $39.7 \%$ after 120 min of treatment time (Table 1). These results suggest that the degradation and mineralization of phenol is partial when only ozonation treatment is applied. It is well known that oxidation by ozone can be either direct or indirect [9]. The former occurs by the ozone molecule and the latter by the production of hydroxyl radicals (reactions (1)-(11)). Once produced, these radicals oxidize the organic molecule. The prevalence of direct or indirect ozonation is mainly a function of $\mathrm{pH}$. As can be seen in Fig. 4, from minute 5 and onwards the solution $\mathrm{pH}$ becomes acid and therefore direct oxidation is expected to prevail. Indeed, the results shown in Fig. 8 confirm that the direct oxidation is the one prevailing in this system 


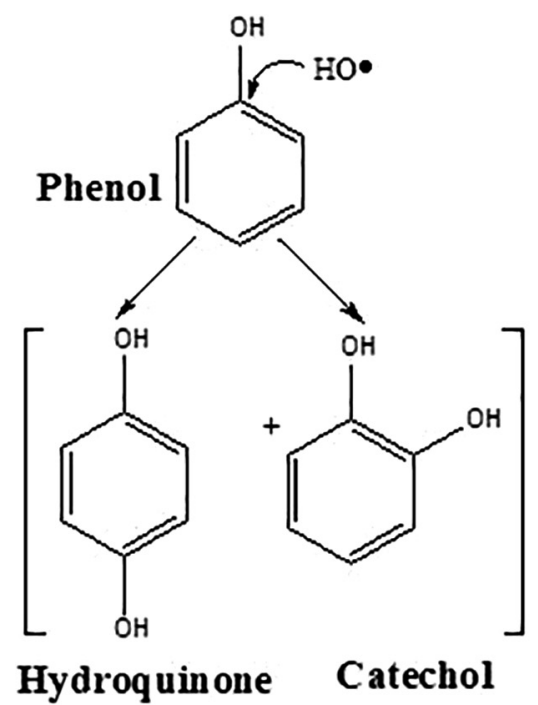<smiles>O=C1C=CC(=O)C=C1</smiles>

p-Benz oquin one<smiles></smiles>

Maleic acid

Fumaric acid

HO•<smiles>O=C(O)C(=O)OCCO</smiles><smiles>O=CO</smiles>

Formic acid

Fig. 6. Proposed phenol degradation pathway during the $\mathrm{O}_{3}$-EO coupled process.

since ozone alone has more limited oxidant power than the hydroxyl radical. Moreover, by analyzing Fig. 8 , it can be concluded that ozone favors the phenol degradation into aliphatic compounds (mainly oxalic acid) and that these are not being further degraded. This concurs with previous reports [39] about the inability of ozone to degrade oxalic acid. From Fig. 3, it can be concluded that the $\mathrm{H}_{2} \mathrm{O}_{2}$ accumulated concentration during the ozonation process is nearly none.

\subsection{Synergy of $\mathrm{O}_{3}-\mathrm{EO}$ process}

As shown in Table 1, the coupled process reduces and practically eliminates the organic pollutant (phenol) and the products of its oxidation. The values of COD and TOC are effectively reduced without any addition of chemical reagents. The coupled process also increases the efficiency of the organic removal and the mineralization time is substantially reduced.

It is evident from the results in Table 1, that among the three tested treatments, ozone is not as effective as electro-oxidation or the coupled process. This can be ascribed to oxidation occurring mainly via hydroxyl radicals in the two last cases while in the case of ozonation, direct oxidation via ozone molecule is prevailing. It can also be observed that the EO process leads to practically phenol mineralization after 120 min (Fig. 9). This, however, does not occur as fast as in the coupled process (Fig. 10). The maximum TOC reduction of $39.7 \%$ and $92.1 \%$ occurs at $120 \mathrm{~min}$, for $\mathrm{O}_{3}$ and $\mathrm{EO}$, respectively. While the TOC reduction with the coupled treatment was $98.5 \%$ after $60 \mathrm{~min}$ and $99.8 \%$ after $120 \mathrm{~min}$. Table 1 also shows the effect of COD reduction. It is observed that at $60 \mathrm{~min}$, the COD reduction was $98.0 \%$ and $99.0 \%$ at 120 min for the $\mathrm{O}_{3}$-EO coupled process. Thus, the coupled process is around twice faster on 


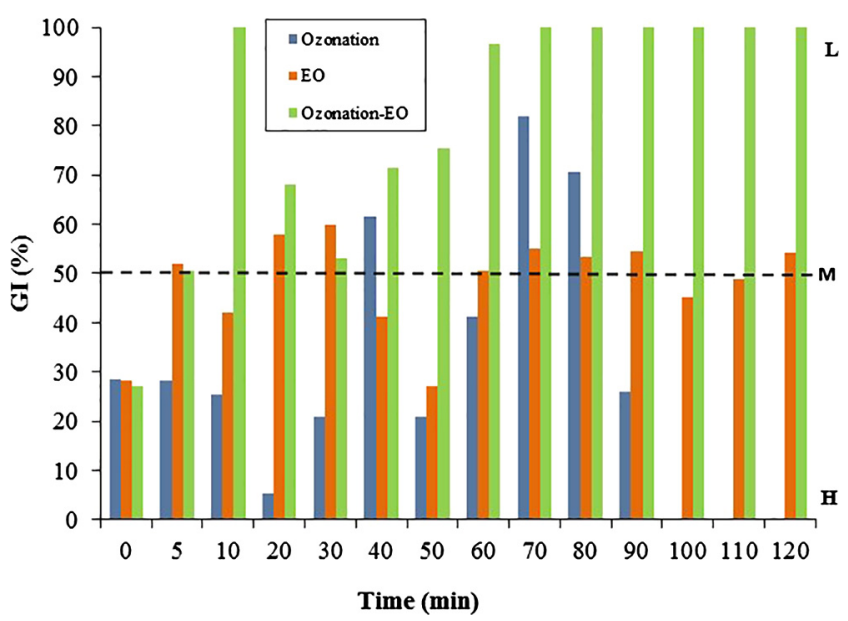

Fig. 7. Effect of type of treatment, Ozonation $\left(\mathrm{O}_{3}\right)$, Electro-oxidation (EO) and coupled ozonation-electrooxidation $\left(\mathrm{O}_{3}-\mathrm{EO}\right)$, on Germination Index of Lactuca sativa (GI\%). L: Low toxicity, M: Moderate toxicity and H: High toxicity or maximum phytotoxicity.

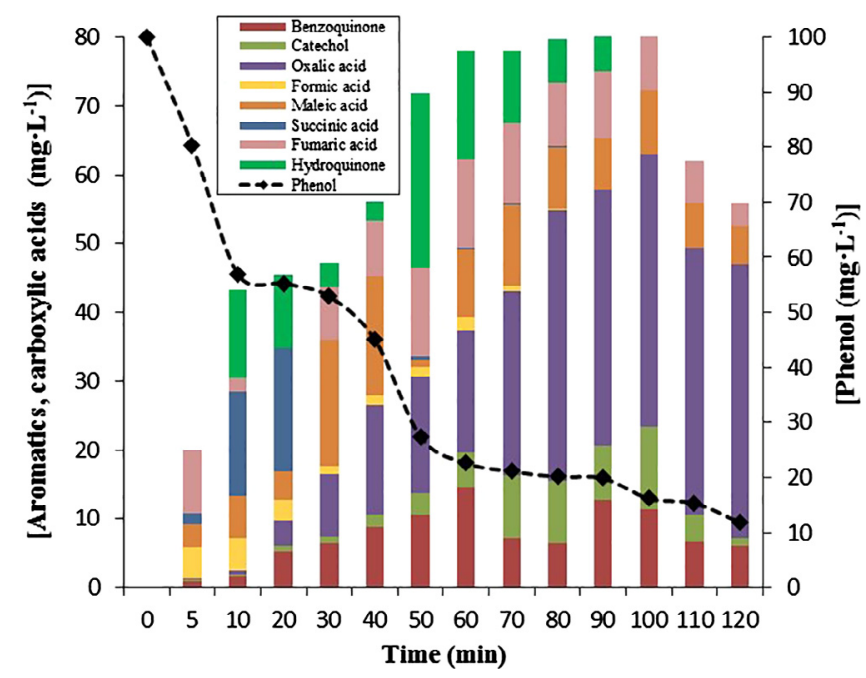

Fig. 8. Effect of $\mathrm{O}_{3}$ on concentration of phenol and products distribution (aromatics and carboxylic acids) during $120 \mathrm{~min}$ of treatment. Initial $\mathrm{pH}=7.0,[\mathrm{Ph}]_{\mathrm{o}}=100$ $\mathrm{mg} \mathrm{L}^{-1}, \mathrm{~V}=0.9 \mathrm{~L}$, [ozone] $=5 \pm 0.5 \mathrm{mg} \mathrm{L}^{-1}$, flowrate of $0.05 \mathrm{~L} \mathrm{~min}^{-1}$.

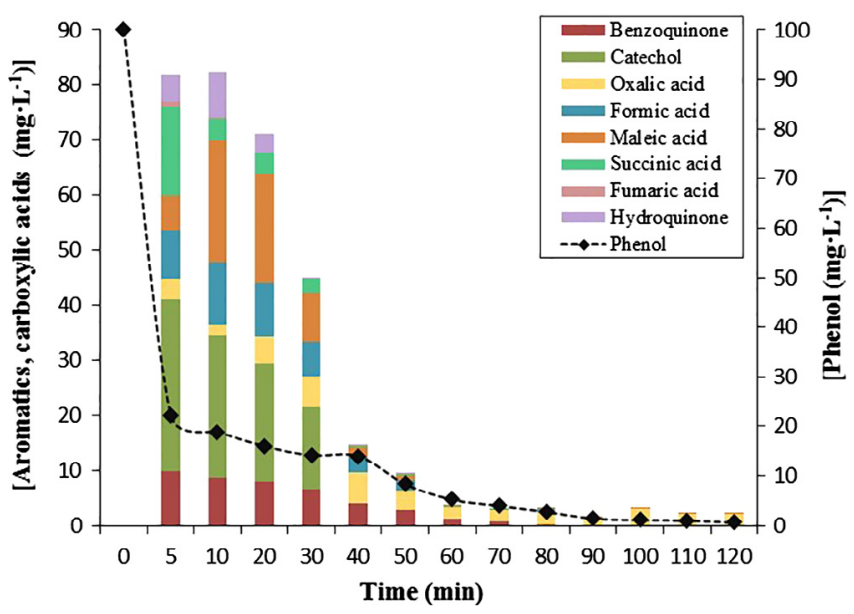

Fig. 9. Effect of EO on concentration of phenol and intermediates (aromatics and carboxylic acid) during $120 \mathrm{~min}$ of treatment. Initial $\mathrm{pH}=7.0,[\mathrm{Ph}]_{\mathrm{o}}=100 \mathrm{mg} \mathrm{L}^{-1}$, $\mathrm{V}=0.9 \mathrm{~L}, j=60 \mathrm{~mA} \mathrm{~cm}{ }^{2}$. mineralizing phenol than the electrochemical treatment alone. This can be ascribed to the two processes $\left(\mathrm{O}_{3}\right.$ and EO) synergistically acting in the coupled process and all the previously discussed reactions for the individual treatments are expected to occur. Therefore, in the combined process, the oxidation of organic compounds does not occur mainly at the anode surface via hydroxyl radicals as in the case of the EO treatment. As previously reported $[23,24]$, besides the substrate elimination, the high oxidation power of BDD allows the concurrent formation of several side products: hydrogen peroxide, peroxodisulphate and ozone (Fig. 5). Hydrogen peroxide $\left(\mathrm{H}_{2} \mathrm{O}_{2}\right)$ comes from the recombination of the HO radicals (reaction (18)) or from the oxygen cathodic reduction (reaction (16)), while peroxodisulphate is formed by the oxidation of sulfate (reaction (19)) and ozone might be generated from water oxidation at the anode (reaction (20)) [40]. The radical $\mathrm{SO}_{4}^{--}$is formed by the reaction between the peroxodisulphate with the electrons generated in the electrode (reaction (21)) $[41,42]$. This radical is a better oxidant than persulphate and oxygen and can trap the generated electrons (reaction (22)). It can also generate hydroxyl radicals (reaction (23)) when reacting with water.

$2 \mathrm{BDD}\left(\mathrm{HO}^{*}\right) \rightarrow 2 \mathrm{BDD}+\mathrm{H}_{2} \mathrm{O}_{2}$

$2 \mathrm{SO}_{4}^{2-} \rightarrow \mathrm{S}_{2} \mathrm{O}_{8}^{2-}+2 e^{-}$

$3 \mathrm{H}_{2} \mathrm{O} \rightarrow \mathrm{O}_{3(\mathrm{~g})}+6 \mathrm{H}^{+}+6 e^{-}$

$\mathrm{S}_{2} \mathrm{O}_{8}^{2-}+e^{-} \rightarrow \mathrm{SO}_{4}^{--}+\mathrm{SO}_{4}^{2-}$

$\mathrm{SO}_{4}^{--}+e^{-} \rightarrow \mathrm{SO}_{4}^{2-}$

$\mathrm{SO}_{4}^{--}+\mathrm{H}_{2} \mathrm{O} \rightarrow \mathrm{HO}+\mathrm{SO}_{4}^{2-}+\mathrm{H}^{+}$

\subsection{Proposed mechanism for phenol degradation during $\mathrm{O}_{3}-E \mathrm{O}$ coupled process}

HPLC analysis of electrolyzed solution allowed the identification of different aromatics and carboxylic acids produced as intermediates during the mineralization of phenol. All the phenol degradation by-products were unequivocally identified by comparing their retention time with the ones from standard compounds. During the degradation of phenol, the hydroxyl radicals can be expected to be added onto the benzene ring at the ortho-, para- or meta-positions to either produce catechol, hydroquinone or resorcinol, accordingly. In this case, however, only the formation of catechol and hydroquinone was observed. These two compounds are likely to be further converted to benzoquinone (Fig. 6). This is in concordance with previous studies related with the mechanism of phenol degradation $[1,25]$.

It can be seen that the main detected aromatic by-products were catechol, hydroquinone, benzoquinone and the detected aliphatic by-products were succinic, maleic, fumaric, formic and oxalic acids (Fig. 10). It is worth noticing that the catechol, hydroquinone and benzoquinone concentration increased in the first $5 \mathrm{~min}$ and then began to decrease till complete removal at $40 \mathrm{~min}$. It can also be noted that the organic acids (succinic, maleic, fumaric, formic and oxalic) reached a maximum concentration at 10 min and consequently pH became acid (Fig. 4). All these carboxylic acids were finally oxidized into carbon dioxide and water as shown in Fig. 10. These results are in good agreement with previous reports $[1,36]$.

Given the above described identifications and evolution of aromatic and aliphatic reaction intermediates, a degradation pathway 
Table 1

Effect of treatment type on Total Carbon (TC), Total Organic Carbon (TOC), Inorganic Carbon (IC) and Chemical Oxygen Demand (COD).

\begin{tabular}{|c|c|c|c|c|}
\hline \multirow[t]{2}{*}{ Total organic carbon analysis } & TC & TOC & IC & COD \\
\hline & \multicolumn{4}{|l|}{$\mathrm{mg} \mathrm{L}^{-1}$} \\
\hline Phenol $\left[C_{o}=100 \mathrm{mg} \mathrm{L}^{-1}\right]$ & $82.2^{\mathrm{a}} \pm 2.5^{\mathrm{b}}$ & $78 \pm 3.8$ & $4.2 \pm 0.5$ & $231 \pm 3.1$ \\
\hline Ozone (120 min) & $48 \pm 2.0$ & $47 \pm 2.1$ & $1 \pm 0.2$ & $83 \pm 5.3$ \\
\hline $\mathrm{BDD}(120 \mathrm{~min})$ & $12 \pm 2.5$ & $6 \pm 1.1$ & $6 \pm 0.9$ & $5 \pm 2.3$ \\
\hline $\mathrm{O}_{3}-\mathrm{BDD}(60 \mathrm{~min})$ & $3.7 \pm 0.4$ & $1.2 \pm 0.1$ & $2.5 \pm 0.1$ & $4 \pm 3.1$ \\
\hline $\mathrm{O}_{3}-\mathrm{BDD}(120 \mathrm{~min})$ & $3.2 \pm 0.5$ & $0.2 \pm 0.3$ & $3 \pm 1.3$ & $2 \pm 0.5$ \\
\hline
\end{tabular}

a TC, TOC, IC and COD values.

b Standard deviation.

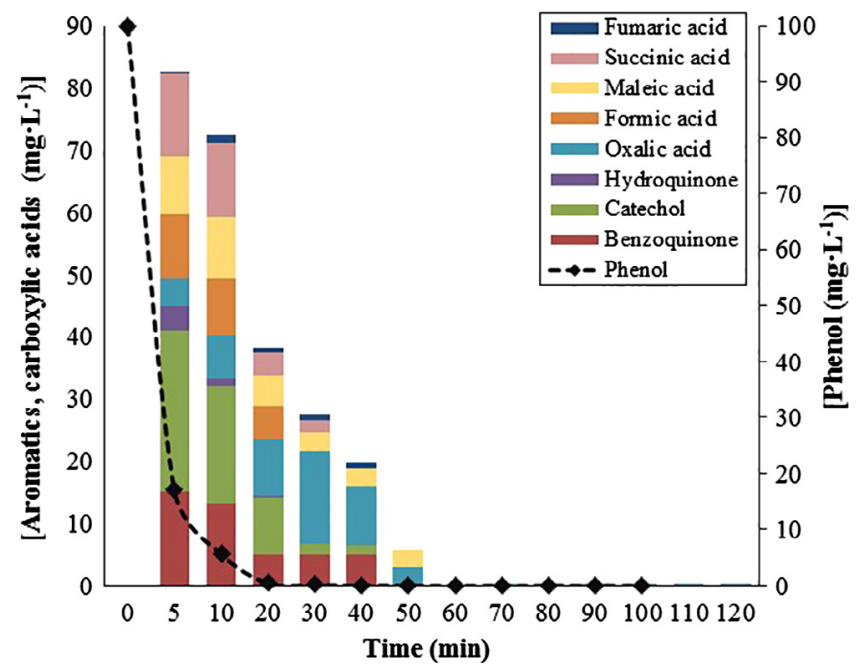

Fig. 10. Effect of $\mathrm{O}_{3}$-EO on concentration of phenol and intermediates (aromatics and carboxylic acid) during $120 \mathrm{~min}$ of treatment. Initial $\mathrm{pH}=7.0,[\mathrm{Ph}]_{\mathrm{o}}=100 \mathrm{mg} \mathrm{L}^{-1}$, $\mathrm{V}=0.9 \mathrm{~L}, j=60 \mathrm{~mA} \mathrm{~cm}{ }^{2}$, [ozone] $=5 \pm 0.5 \mathrm{mg} \mathrm{L}^{-1}$, flowrate of $0.05 \mathrm{~L} \mathrm{~min}^{-1}$.

for phenol mineralization by $\mathrm{O}_{3}$-EO coupled process is proposed in Fig. 6.

\subsection{Toxicity test}

\subsubsection{Effect of $\mathrm{O}_{3}$ process on toxicity}

In the control samples of each treatment, the highest seeds germination percentage was $>90 \%$. It is also worth pointing out that the seeds showed a normal growth without defects, with a root elongation of $30 \%(C V=3.44 \%)$.

The GI values of the phenolic solution treated with ozone (Fig. 7), showed that the moderated phytotoxicity observed during the first $40 \mathrm{~min}$ of treatment is temporary reduced during the next $45 \mathrm{~min}$ of reaction. Nevertheless, the solution becomes highly toxic after $85 \mathrm{~min}$ of reaction and this can be ascribed to the produced carboxylic acids (mainly oxalic acid) not being further oxidized during the ozonation process (see Fig. 8) and this also lowers pH (see Fig. 4). Although the toxicity of carboxylic acids (i.e., formic, acetic, propionic, butyric, valeric, and caproic acids) has already been documented [43], the observed toxicity could be thought to be due to $\mathrm{pH}$. Nevertheless, the effect of $\mathrm{pH}$ on toxicity can be ruled out until certain point by contrasting the $\mathrm{pH}$ evolution (Fig. 4) with germination index (Fig. 7). It can be observed, for instance, that at minute 20 the $\mathrm{pH}$ of the solution treated by $\mathrm{O}_{3}$ and $\mathrm{O}_{3}$-EO is very similar (about 3.5) while GI is notoriously different (5\% for the solution treated with $\mathrm{O}_{3}$ and nearly $70 \%$ for the solution treated with the combined process). A similar analysis can be conducted between the results obtained with $\mathrm{EO}$ and $\mathrm{O}_{3}$-EO at $50 \mathrm{~min}$ of treatment. $\mathrm{pH}$ at this point is approximately 5.3 in both cases while GI is $25 \%$ for the former and $75 \%$ for the latter. Thus, because of the results shown in Fig. 7, it can be concluded that ozonation not only fails on diminishing phytotoxicity but actually results to be lethal to Lactuca sativa.

\subsubsection{Effect of EO process on toxicity}

According to HPLC analysis of the samples obtained during the EO process (Fig. 9), after 5 min of treatment, aromatic compounds (hydroquinone, catechol and benzoquinone) and organic acids (succinic, formic, oxalic, maleic and fumaric acid) were produced. Unlike the combined process, hydroquinone was observed in higher quantity at all times. According to Fig. 7, during the first 30 min of treatment, there is also an increase on GI that indicates the toxicity becomes lower. After $40 \mathrm{~min}$ of treatment, the organic acids are in greater concentration than the aromatic products. These acids are transformed into oxalic acid and this is the only remaining acid into solution even after $120 \mathrm{~min}$ of treatment. In consequence, $\mathrm{pH}$ solution decreases from 7 (at reaction time $=0$ ) to 4.5 (at $\mathrm{t}=30 \mathrm{~min}$ ). After $110 \mathrm{~min}$ of reaction, however, $\mathrm{pH}$ increases again to 7 . This may be suggesting the appearance of alkaline compounds like carbonates or bicarbonates most likely as a result of phenol mineralization. Regarding aromatic compounds (benzoquinone, catechol, hydroquinone and phenol), these are in larger proportion than carboxylic acids until 40 min of treatment is reached. At this point, there is a change in degradation and only benzoquinone is in appreciable concentration. It can be concluded that benzoquinone is the precursor of the organic acids. It can also be concluded that with the electrochemical process the phytotoxicity of the solution remains within a moderate range albeit a high degree of oxidation is observed. This can ascribed to the presence of oxalic acid mainly.

\subsubsection{Effect of coupled $\mathrm{O}_{3}-E O$ process on toxicity}

Unlike ozonation, after the first 5 min of applying the coupled treatment the appearance of species such as catechol and benzoquinone is observed (Fig. 10). Actually the by-product with the highest concentration was catechol. Nevertheless, catechol is readily degraded from $5 \mathrm{~min}$ and onwards. Oxalic acid concentration finds a maximum at around $30 \mathrm{~min}$ and then is readily degraded. In concordance, after 40 min only oxalic and maleic acid remain only for few further minutes and therefore $\mathrm{pH}$ increases to 6 (Fig. 4) and toxicity is totally eliminated (Fig. 7).

Fig. 7 shows the effect of treatment on GI. It is worth remembering that GI values near to $100 \%$ are associated to a high seed germination and radicle elongation and therefore such values are associated to a minimum or not existent toxicity. The coupled $\mathrm{O}_{3}$-EO process leads to $\mathrm{GI}>90 \%$ after $60 \mathrm{~min}$ of treatment, followed by the electrochemical process ( $\mathrm{GI}=50 \%$ ) and finally the ozonation process with $\mathrm{GI}=0 \%$ (development of the seed was completely inhibited) at the end of treatment. Hence, it can be concluded that among the studied processes, only the coupled $\mathrm{O}_{3}$-electrochemical treatment is able to eliminate the phytotoxicity effects of the phenolic solution. 


\section{Conclusions}

The combination of $\mathrm{EO}$ and $\mathrm{O}_{3}$ processes results in a synergy that greatly enhances the rate and extent of phenol mineralization. EO alone reduces $97.7 \%$ of COD and $92.1 \%$ of TOC. It requires, however, a relatively long time and the solution final toxicity is moderate. On the other hand, $\mathrm{O}_{3}$ alone only reduces $63.3 \%$ of $\mathrm{COD}$ and $39.7 \%$ of TOC at also relatively long treatment times. The ozonation process alone not only fails on phenol mineralization but also on diminishing toxicity. When the coupled $\mathrm{O}_{3}$-EO process is used, a maximum COD reduction of $98.0 \%$ and $98.5 \%$ of TOC occurs after half of the other treatment times. The conditions at which the highest COD and TOC removals can be achieved are $\mathrm{pH} 7.0 \pm 0.05$, with $5 \pm 0.5 \mathrm{mg} \mathrm{L}^{-1}$ of ozone concentration, $60 \mathrm{~mA} \mathrm{~cm}^{-2}$ of current density and temperature of $20^{\circ} \mathrm{C} \pm 0.05$. From HPLC analysis, the degradation products were established and a degradation pathway of phenol during $\mathrm{O}_{3}$-EO coupled process was proposed. From the point of view of toxicity, the EO treatment is not recommended for molecules which main degradation product is oxalic acid. Among the studied treatments, only the coupled treatment fully eliminates the toxicity effects of the treated phenolic solution onto Latuca sativa. The toxicity is mainly exerted by oxalic acid. The reluctance of oxalic acid to be oxidized by either electro-oxidation or ozonation alone can be overcome by the combination of both.

\section{Acknowledgments}

The authors wish to acknowledge the support given by the Joint Center for Research in Sustainable Chemistry, UAEMex-UNAM. Financial support from CONACYT through project 168305 and scholarship 276534 is greatly appreciated. The technical support of Citlalit Martinez Soto is greatly appreciated.

\section{Appendix A. Supplementary material}

Supplementary data associated with this article can be found, in the online version, at http://dx.doi.org/10.1016/j.fuel.2016.10.117.

\section{References}

[1] Yang X, Zou R, Huo F, Cai D, Xiao D. Preparation and characterization of Ti/ $\mathrm{SnO}_{2}-\mathrm{Sb}_{2} \mathrm{O}_{3}-\mathrm{Nb}_{2} \mathrm{O}_{5} / \mathrm{PbO}_{2}$ thin film as electrode material for the degradation of phenol. J Hazard Mater 2009;164:367-73.

[2] Abaci S, Tamer U, Pekmez K, Yildiz A. Performance of different crystal structures of $\mathrm{PbO}_{2}$ on electrochemical degradation of phenol in aqueous solution. Appl Surf Sci 2005;240:112-9.

[3] Ma H, Zhang X, Ma Q, Wang B. Electrochemical catalytic treatment of phenol wastewater. J Hazard Mater 2009;165:475-80.

[4] Zhu X, Tong M, Shi S, Zhao H, Ni J. Essential explanation of the strong mineralization performance of boron-doped diamond electrodes. Environ Sci Technol 2008;47:4914-20.

[5] Zhuo Q, Deng S, Yang B, Huang J, Yu G. Efficient electrochemical oxidation of perfluorooctanoate using a $\mathrm{Ti} / \mathrm{SnO}_{2}-\mathrm{Sb}-\mathrm{Bi}$ anode. Environ Sci Technol 2011;45:2973-9.

[6] Wei J, Feng Y, Sun X, Liu J, Zhu L. Effectiveness and pathways of electrochemical degradation of pretilachlor herbicides. J Hazard Mater 2011;189:84-91.

[7] Zhu X, Ni J, Lai P. Advanced treatment of biologically pretreated coking wastewater by electrochemical oxidation using boron-doped diamond electrodes. Water Res 2009;43:4347-55.

[8] Beltran F. Ozone reaction kinetics for water and wastewater systems. London; 2003.

[9] de Heredia Beltrán J, Domínguez JR, Lopez R. Advanced oxidation of corkprocessing wastewater using Fenton's reagent: kinetics and stoichiometry. J Chem Technol Biotechnol 2004:79:407-12.

[10] Hoigné J, Bader H. The role of hydroxyl radical reactions in ozonation processes in aqueous solutions. Water Res 1976;10:377-86.

[11] Alvares AB, Diaper C, Parsons SA. Partial oxidation by ozone to remove recalcitrance from wastewaters - a review. Environ Technol 2001;22:409-27.

[12] Tomiyasu H, Fukutomi H, Gordon G. Kinetics and mechanism of ozone decomposition in basic aqueous solution. Inorg Chem 1985;24:2962-6.

[13] Bernal-Martínez LA, Barrera-Díaz C, Solís-Morelos C, Natividad R. Synergy of electrochemical and ozonation processes in industrial wastewater treatment. Chem Eng J 2010;165:71-7.
[14] García-Morales MA, Roa-Morales G, Barrera-Díaz C, Bilyeu B, Rodrigo MA. Synergy of electrochemical oxidation using boron-doped diamond (BDD) electrodes and ozone (O3) in industrial wastewater treatment. Electrochem Commun 2013;27:34-7.

[15] Qiu C, Yuan S, Li X, Wang H, Bakheet B, Komarneni S, et al. Investigation of the synergistic effects for p-nitrophenol mineralization by a combined process of ozonation and electrolysis using a boron-doped diamond anode. J Hazard Mater 2014;280:644-53.

[16] Rosales Landeros C, Barrera Díaz CE, Amaya Cháves A, Roa Morales G. Evaluation of a coupled system of electro-oxidation and ozonation to remove the pesticide Thiodan ${ }^{\circledR} 35$ CE (endosulfan) in aqueous solution. Fuel 2016:6-13.

[17] Elaoud SC, Panizza M, Cerisola G, Mhiri T. Electrochemical degradation of sinapinic acid on a BDD anode. Desalination 2011;272:148-53.

[18] Chen J-L, Chiou G-C, Wu C-C. Electrochemical oxidation of 4-chlorophenol with granular graphite electrodes. Desalination 2010;264:92-6.

[19] Vlyssides A, Papaioannou D, Loizidoy M, Karlis P, Zorpas A. Testing an electrochemical method for treatment of textile dye wastewater. Waste Manage 2000;20:569-74.

[20] Chatzisymeon E, Fierro S, Karafyllis I, Mantzavinos D, Kalogerakis N Katsaounis A. Anodic oxidation of phenol on $\mathrm{Ti} / \mathrm{IrO}_{2}$ electrode: experimental studies. Catal Today 2010;151:185-9.

[21] Tran L-H, Drogui P, Mercier G, Blais J-F. Electrochemical degradation of polycyclic aromatic hydrocarbons in creosote solution using ruthenium oxide on titanium expanded mesh anode. J Hazard Mater 2009;164:1118-29.

[22] $\mathrm{Hu}$ F, Cui X. Chenz W. Pulse electro-codeposition of $\mathrm{Ti} / \mathrm{SnO}_{2}-\mathrm{Sb}_{2} \mathrm{O}_{4}-\mathrm{CNT}$ electrode for phenol oxidation. Electrochem Solid-State Lett 2010;13:F20-3.

[23] Samet Y, Agengui L, Abdelhédi R. Anodic oxidation of chlorpyrifos in aqueous solution at lead dioxide electrodes. J Electroanal Chem 2010;650:152-8.

[24] Song S, Zhan L, He Z, Lin L, Tu J, Zhang Z, et al. Mechanism of the anodic oxidation of 4-chloro-3-methyl phenol in aqueous solution using $\mathrm{Ti} / \mathrm{SnO}_{2}-\mathrm{Sb} /$ $\mathrm{PbO}_{2}$ electrodes. J Hazard Mater 2010;175:614-21.

[25] Azizi O, Hubler D, Schrader G, Farrell J, Chaplin BP. Mechanism of Perchlorate Formation on Boron-Doped Diamond Film Anodes 2011:10582-90.

[26] Radjenovic J, Sedlak DL. Challenges and opportunities for electrochemical processes as next-generation technologies for the treatment of contaminated water challenges and opportunities for electrochemical processes as nextgeneration technologies for the treatment of contaminate; 2015.

[27] Bakheet B, Yuan S, Li Z, Wang H, Zuo J, Komarneni S, et al. Electro-peroxone treatment of Orange II dye wastewater. Water Res 2013:1-10.

[28] Panizza M, Brillas E, Comninellis C. Application of Boron-Doped Diamond electrodes for wastewater treatment 2008;18:139-53.

[29] Marselli B, Garcia-Gomez J, Michaud P-A, Rodrigo MA, Comninellis Ch. Electrogeneration of hydroxyl radicals on boron-doped diamond electrodes. J Electrochem Soc 2003;150:D79-83.

[30] Carrillo EG, Haro-Vázquez MP, Díaz-Trujillo GC, Cañizares-Macías MP. Plackett-Burman factorial design for the optimization of a spectrophotometric flow injection method for phenol determination in tap and bottled water using 4-aminoantipyrine. J Mex Chem Soc 2014;58:99-105.

[31] Association APH. APHA, AWWA, Standard methods for the examination of water and wastewater, 16th ed. Washington DC; 1995.

[32] Eisenberg G. Colorimetric determination of hydrogen peroxide. Ind Eng Chem Anal Ed 1943;15:327-8.

[33] Dutka BJ, Kwan KK, Rao SS, Jurkovic A, McInnis R, GAP, et al. Use of bioassays to evaluate river water and sediment quality. Environ Toxicol Water Qual 1991:309-27.

[34] Hoekstra NT, Bosker TY, Lantinga EA. Effects of cattle dung from farms with different feeding strategies on germination and initial root growth of cress (Lepidium sativum L.). Agric Ecosys Environ 2002;93:189-96.

[35] Walter I, MF yCV. Heavy metal speciation and phytotoxic effects of three representative sewage sludges for agricultural uses. Environ Pollut 2006;139:507-14

[36] Iniesta J. Electrochemical oxidation of phenol at boron-doped diamond electrode. Electrochim Acta 2001;46:3573-8.

[37] Peralta E, Natividad R, Roa G, Marin R, Romero R, Pavon T. A comparative study on the electrochemical production of $\mathrm{H}_{2} \mathrm{O}_{2}$ between BDD and graphite cathodes. Sustainable Environ Res 2013;23:259-66.

[38] Espinoza-montero PJ, Vasquez-medrano R, Ibanez JG, Frontana-uribe BA Efficient anodic degradation of phenol paired to improved cathodic production of $\mathrm{H}_{2} \mathrm{O}_{2}$ at BDD electrodes. J Electrochem Soc 2013;160. 0-6.

[39] Martínez CA, Rodrigo MA, Sire I, Scialdone O. Single and coupled electrochemical processes and reactors for the abatement of organic water pollutants: a critical review. Chem Rev 2015.

[40] Guinea E, Centellas F, Garrido JA, Rodríguez RM, Arias C, Cabot P-L, et al. Solar photoassisted anodic oxidation of carboxylic acids in presence of $\mathrm{Fe}^{3+}$ using a boron-doped diamond electrode. Appl Catal B Environ 2009;89:459-68.

[41] Brillas Enric, Martínez-Huitle Carlos Alberto, editors. Synthetic diamond films: preparation, electrochemistry, characterization, and applications. John Wiley \& Sons, Inc.; 2011.

[42] Melián EP, Díaz OG, Rodríguez JMD, Araña J, Peña JP. Adsorption and photocatalytic degradation of 2,4-dichlorophenol in $\mathrm{TiO}_{2}$ suspensions. Effect of hydrogen peroxide, sodium peroxodisulphate and ozone. Appl Catal A Gen 2013;455:227-33.

[43] Himanen M, Prochazka P, Hänninen K, Oikari A. Phytotoxicity of low-weight carboxylic acids. Chemosphere 2012;88:426-31. 